\title{
$A b$ initio study of aluminium impurity and interstitial-substitutional complexes in Ge using hybrid functional (HSE)
}

\author{
E. Igumbor • R. E. Mapasha • W. E. Meyer
}

\begin{abstract}
The results of an $a b$ initio modelling of aluminium substitutional impurity $\left(\mathrm{Al}_{\mathrm{Ge}}\right)$, aluminium interstitial in $\mathrm{Ge}\left(\mathrm{I}_{\mathrm{Al}}\right.$ for the tetrahedral $(\mathrm{T})$ and hexagonal $(\mathrm{H})$ configurations) and aluminium interstitial-substitutional pairs in $\mathrm{Ge}\left(\mathrm{I}_{\mathrm{Al}} \mathrm{Al}_{\mathrm{Ge}}\right)$ are presented. For all calculations, the hybrid functional of Heyd, Scuseria, and Ernzerhof (HSE06) in the framework of density functional theory (DFT) was used. Defects formation energies, charge state transition levels and minimum energy configurations of the $\mathrm{Al}_{\mathrm{Ge}}, \mathrm{I}_{\mathrm{Al}}$ and $\mathrm{I}_{\mathrm{Al}} \mathrm{Al}_{\mathrm{Ge}}$ were obtained for $-2,-1,0,+1$ and +2 charge states. The calculated formation energy shows that for the neutral charge state, the $\mathrm{I}_{\mathrm{Al}}$ is energetically more favourable in the $\mathrm{T}$ than the $\mathrm{H}$ configuration. The $\mathrm{I}_{\mathrm{Al}} \mathrm{Al}_{\mathrm{Ge}}$ forms with forma-

E. Igumbor

Department of Physics, University of Pretoria, Pretoria 0002, South Africa

Department of Mathematical and Physical Sciences, Samuel Adegboyega University, Ogwa

Edo State Nigeria

Tel.: +27-61-7364053

E-mail: elgumuk@gmail.com

R. E. Mapasha

Department of Physics, University of Pretoria, Pretoria 0002, South Africa

W. E. Meyer

Department of Physics, University of Pretoria, Pretoria 0002, South Africa

Tel.: +27-12-4202637

Fax: +123-12-3625288

E-mail: wmeyer@up.ac.za
\end{abstract}


tion energies of -2.37 and $-2.32 \mathrm{eV}$, when the interstitial atom is at the $\mathrm{T}$ and $\mathrm{H}$ sites, respectively. The $\mathrm{I}_{\mathrm{Al}} \mathrm{Al}_{\mathrm{Ge}}$ is energetically more favourable when the interstitial atom is at the $\mathrm{T}$ site with a binding energy of $0.8 \mathrm{eV}$. The $\mathrm{I}_{\mathrm{Al}}$ in the $\mathrm{T}$ configuration, induced a deep donor $(+2 /+1)$ level at $\mathrm{E}_{\mathrm{V}}-0.23 \mathrm{eV}$ and the $\mathrm{Al}_{\mathrm{Ge}}$ induced a single acceptor level $(0 /-1)$ at $\mathrm{E}_{\mathrm{V}}-0.15 \mathrm{eV}$ in the band gap of Ge. The $\mathrm{I}_{\mathrm{Al}} \mathrm{Al}_{\mathrm{Ge}}$ induced double donor levels are at $\mathrm{E}_{\mathrm{V}}+0.06$ and $\mathrm{E}_{\mathrm{V}}+0.12 \mathrm{eV}$, when the interstitial atom is at the $\mathrm{T}$ and $\mathrm{H}$ sites, respectively. The $\mathrm{I}_{\mathrm{Al}}$ and $\mathrm{I}_{\mathrm{Al}} \mathrm{Al}_{\mathrm{Ge}}$ exhibits properties of charge state controlled metastability.

Keywords Defect $\cdot$ formation energy $\cdot$ charge state $\cdot$ impurity

\section{Introduction}

One of the most recent semiconductor materials that is attracting great interest in the field of microelectronic is germanium (Ge) [1]. Ge has a narrow band gap of $0.78 \mathrm{eV}[2]$ and exhibits electron-hole mobility that is higher than silicon $(\mathrm{Si})$ [1], which makes it a promising material for the development of $\mathrm{Ge}$ metal-oxide semiconductor field effect transistors (MOSFETs). Despite the interesting application of Ge in the field of microelectronic, there are several challenges surrounding its successful implementation as MOSFETs [1]. Claeys and Simoen (2011) [1] in a detailed report, highlighted the possible future direction for semiconductor industry and the probably role that Ge can play. Point defects in semiconductors have been reported to influence the quality of devices performance either positively or negatively [1]. The in-depth knowledge of defect formation and charge state transition energy levels are of interest towards controlling and engineering their formation in order to improve the material quality. In recent time, there have been great improvement towards discovery, identifying and investigation of several point defects by experimental tech- 
niques [3-6] or theoretical modelling [7-9]. By using density functional theory (DFT) $[10,11]$, point defects such as self-interstitial [12], vacancies [13], diinterstitials [14], substitutional impurities $[15,16]$ and vacancy-complexes [17, 18] in Ge had been reported. Point defects in several materials are known to also exist in the form of interstitial-substitutional pairs. For example, the interstitial-iron-substitutional-aluminium $\left(\mathrm{Fe}_{i} \mathrm{Al}_{s}\right)$ pair in silicon [19] and the carbon-substitutional-carbon-interstitial $\left(\mathrm{C}_{s} \mathrm{C}_{i}\right)$ defect in silicon [20] have been identified by experimental techniques. One important result of the $\mathrm{Fe}_{i} \mathrm{Al}_{s}$ and $\mathrm{C}_{s} \mathrm{C}_{i}$, is that they are metastable. A defect or defect complex is said to be metastable when the defect or defect complexes with different atomic configurations ( $\mathrm{X}$ and $\mathrm{Y}$ ), where configuration $\mathrm{X}$, is the minimum energy in a particular charge state, and configuration $\mathrm{Y}$, is stable in a different charge state. Recently, theoretical results of Al interstitial and substitution in Si had been reported by Shi et al [21]. Al atom in $\mathrm{Si}$ bulk prefers to substitute $\mathrm{Si}$ rather than to be an interstitial [21]. Al is a shallow acceptor in $\mathrm{Si}$, and it is a common dopant that have been used to produced $p$-type Si [21]. Despite major breakthroughs in identifying and predicting the charge state transition levels of several defects in their host, there are still more to be investigated either using experimentally technique or theoretical methods. For instance, the electrical activities of aluminium $(\mathrm{Al})$ interstitial-substitutional pairs in Ge, doping of Ge by $\mathrm{Al}$ and other $\mathrm{Al}$ related point defects in Ge have not been fully investigated. In order to provide an insight on how to control the electrical activities of shallow, deep levels and charge state controlled metastability of $\mathrm{Al}$ related defects in $\mathrm{Ge}$, detail formation energies and charge state transition energy level calculations are required.

In this report, we present results of the $\mathrm{Al}$ impurity $\left(\mathrm{Al}_{\mathrm{Ge}}\right), \mathrm{Al}$ interstitial in Ge $\left(\mathrm{I}_{\mathrm{Al}}\right)$ and aluminium substitutional-interstitial pairs in $\mathrm{Ge}\left(\mathrm{I}_{\mathrm{Al}} \mathrm{Al}_{\mathrm{Ge}}\right)$ using the hybrid functional of Heyd, Scuseria, and Ernzerhof (HSE) [22] under the 
framework of DFT. We calculated the structural and electronic properties of $\mathrm{Ge}$ and $\mathrm{Al}$ related defects in $\mathrm{Ge}$, as well as their formation energies with a view to finding the most energetically stable configuration. The charge state transition levels induced by $\mathrm{Al}$ related defects in the band gap of Ge were obtained. We shown that the $\mathrm{Al}$ interstitial and the $\mathrm{I}_{\mathrm{Al}} \mathrm{Al}_{\mathrm{Ge}}$ exhibit charge state controlled metastability.

\section{Computational details}

DFT electronic structure calculations were performed using the the Vienna $a b$ - initio Simulation Package (VASP) [23,24]. The valence electrons were separated from the core electrons using the projector-augmented wave (PAW), as implemented in the VASP code [24-26]. All calculations were carried out using the Heyd, Scuseria, and Ernzerhof (HSE) [22] hybrid functional. In HSE hybrid functional, the short-range exchange potential was calculated by mixing a fraction $(25 \%)$ of nonlocal Hartree-Fock exchange with the generalized gradient approximation (GGA) functional of Perdew, Burke, and Ernzerhof (PBE) [27]. In contrast to the local density approximation (LDA) and the GGA that underestimate the band gap of semiconductors [28-30], the HSE06 hybrid functional gives an excellent description of the electronic band gap and improved charge state transition properties for a wide range of defects in group-IV semiconductors $[8,14,28]$. For the pristine, a 64 atom supercell was used. For the $\mathrm{Al}_{\mathrm{Ge}}$ defect, an $\mathrm{Al}$ atom was substituted in place of $\mathrm{Ge}$ in the 64 atom supercell. For the aluminium substitutional-interstitial pairs $\left(\mathrm{I}_{\mathrm{Al}} \mathrm{Al}_{\mathrm{Ge}}\right)$, an $\mathrm{Al}$ atom was substituted in place of a $\mathrm{Ge}$ atom and another $\mathrm{Al}$ atom was placed in an interstitial site in a 64 atom supercell. A $2 \times 2 \times 2$ Monkhorst-Pack special k-point Brillouin zone sampling scheme was used for both the pristine and defect calculations. For all calculations, the plane wave cut-off of the wave 
function expansion was set to $400 \mathrm{eV}$. We refined the geometric structures until the final change in the total energy and forces were less than $10^{-5} \mathrm{eV}$ and $0.001 \mathrm{eV} / \AA$, respectively. Spin orbit coupling was taken into account in all the calculations.

The concentrations (C) of defect in thermodynamic equilibrium is related to the formation energy $\left(E^{f}\right)$ through the Boltzmann constant $\left(k_{B}\right)$

$$
C=N_{0} \exp \left(-E^{f} / k_{B} T\right)
$$

where $T$ is temperature in Kelvin and $N_{0}$ is the number of sites in the crystal where the defect can occur per unit volume. To calculate the formation energy $\left(E^{f}\right)$ of a defect and the charge state transition energy $\left(\epsilon\left(q / q^{\prime}\right)\right)$ level, we calculated the total energy $E(d, q)$ for a supercell containing the optimized defect $d$ in its charge state $q$. For any band gap $E_{g a p}$, the Fermi energy denoted as $\left(\varepsilon_{F}\right)$ is measured from the valence band maximum $E_{V}(\mathrm{VBM})$ as

$$
E_{V} \leq \varepsilon_{F} \leq E_{V}+E_{g a p}
$$

The defect formation energy $E^{f}(d, q)$ as a function of electron Fermi energy $\left(\varepsilon_{F}\right)$ is given as $[31,32]$

$$
E^{f}(d, q)=E(d, q)-E(\text { pure })+\sum_{i} \triangle(n)_{i} \mu_{i}+q\left[E_{V}+\varepsilon_{F}\right]+E_{F N V}^{q}
$$

where $E($ pure $)$ is the energy of a supercell without a defect, $\triangle(n)_{i}$ is the difference in the number of constituent atoms of type $i$ between the pristine and defect supercells $\left(\triangle(n)_{i}<0\right.$ or $\triangle(n)_{i}>0$ when an impurity is added or removed from the host supercell) and $\mu_{i}$ is the chemical potential of type $i t h$ atom. The $E_{F N V}^{q}$ is the Freysoldt, Neugebauer and Van de Walle (FNV) correction term, which accounts for the potential alignment between the charged 
defect and bulk at a point far from the defect and charge corrections in a supercell of finite-size $[33,34]$. The FNV scheme explicitly uses the electrostatic potential obtained from DFT calculations to obtain an electrostatics model. An increase in the formation energy of a defect obtained from Eq. 3 leads to a decrease in the concentration of a defect and thus, the defect becomes energetically less favourable. The defect charge state transition energy level $\epsilon\left(q / q^{\prime}\right)$ is the Fermi energy for which the formation energy of charge state $q$ equals that of charge state $q^{\prime}$, and is given as [32]

$$
\epsilon\left(q / q^{\prime}\right)=\frac{E^{f}\left(d, q ; \varepsilon_{F}=0\right)-E^{f}\left(d, q^{\prime} ; \varepsilon_{F}=0\right)}{q^{\prime}-q}
$$

The binding energy $E_{b}$ which is defined as the energy required to split up a cluster into well separated non-interacting defects is given as [35]

$$
E_{b}=\sum_{i} E_{(\text {isolated })}^{f}-E_{(\text {defect-complex })}^{f}
$$

where $\sum_{i} E_{(\text {isolated })}^{f}$ is the sum of formation energies of $i$ th isolated defects and the $E_{(\text {defect-complex })}^{f}$ is the formation energy of a defect-complex. Eq. 5 could be interpreted as the energy loss of the bonded structure with respect to the isolated components.

\section{Results and discussion}

3.1 Structural properties of $\mathrm{Al}$ impurities and interstitial-substitutional complexes in Ge

Fig. 1 shows the relaxed geometric structures of the $\mathrm{I}_{\mathrm{Al}}$ in the tetrahedral $(\mathrm{T})$ and hexagonal $(\mathrm{H})$ configurations, $\mathrm{Al}_{\mathrm{Ge}}$ and $\mathrm{I}_{\mathrm{Al}} \mathrm{Al}_{\mathrm{Ge}}$ interstitial-substitutional pairs (when the interstitial atom is at the tetrahedral site $(\mathrm{T})$ and hexagonal site $(\mathrm{H}))$. After structural relaxation, we found the bond length between 
Ge-Ge atoms nearest neighbour and the bond angle formed between three Ge atoms to be $2.46 \AA$ and $109.40^{\circ}$, respectively, which are in close agreement with results reported by Chroneos at al. [36]. For the $\mathrm{I}_{\mathrm{Al}}$ (see Figs. 1a and 1b for the relaxed geometric structures) in the $\mathrm{T}$ and $\mathrm{H}$ configurations, the average bond lengths between $\mathrm{Al}$ and the nearest neighbour Ge atoms are 2.57 and $2.58 \AA$, respectively. These bond lengths are at least $0.11 \AA$ higher than that of the Ge-Ge atoms bond length. The bond angle formed by $\mathrm{Al}$ atom and the nearest neighbour Ge atoms are $109.5^{\circ}$ and $109.6^{\circ}$ for the $\mathrm{T}$ and $\mathrm{H}$ configurations, respectively. Fig. 1c presents the relaxed geometric structure of the $\mathrm{Al}_{\mathrm{Ge}}$. The shortest $\mathrm{Al}-\mathrm{Ge}$ atoms bond length is $0.02 \AA$ less than the Ge-Ge atoms bond length and the $\mathrm{Ge}-\mathrm{Al}-\mathrm{Ge}$ atoms bond angle is $109.5^{\circ}$. Fig. 1d displays the relaxed geometric structure of the $\mathrm{I}_{\mathrm{Al}} \mathrm{Al}_{\mathrm{Ge}}$, when the interstitial atom is at the $\mathrm{T}$ site and Fig. 1e for same defect but when the interstitial atom is at the $\mathrm{H}$ site. For the $\mathrm{I}_{\mathrm{Al}} \mathrm{Al}_{\mathrm{Ge}}$, when the interstitial atom is at the $\mathrm{T}$ site, the $\mathrm{Al}-\mathrm{Ge}$ atoms average bond length is $2.43 \AA$ and the $\mathrm{Ge}-\mathrm{Al}-\mathrm{Ge}$ average bond angle is $109.7^{\circ}$. When the interstitial atom is at the $\mathrm{H}$ site, the $\mathrm{Al}-\mathrm{Ge}$ average bond length is $2.44 \AA$ and the $\mathrm{Ge}-\mathrm{Al}-\mathrm{Ge}$ average bond angle is $109.8^{\circ}$

3.2 Electronic properties of $\mathrm{Ge}, \mathrm{Al}$ impurities and interstitial-substitutional complexes in $\mathrm{Ge}$

The plot of spin polarised partial density of states (PDOS) and total density of states (DOS) of Ge, the $\mathrm{Al}$ impurities and interstitial-substitutional complexes in Ge are shown in Fig. 2. The PDOS and total DOS are shown on the left and right sides, respectively of Fig. 2. The majority (spin-up) and minority (spin-down) density of states are shown as right and left halves of each plot, respectively. For the pristine Ge, the majority and minority spins 
are symmetrical for the entire plot as shown in Figs. 2a and 2b, suggesting non-spin polarization of the system. The plots Figs. 2c to $2 \mathrm{l}$ show that $\mathrm{Al}$ related defects display non-spin polarisation character. The $\mathrm{I}_{\mathrm{Al}}$ experienced orbital hybridization between the $p$ and $s$-orbitals of Ge and Al. For the $\mathrm{I}_{\mathrm{Al}}$, the plot of the PDOS (see Figs. 2c and 2e) shows that the $p$-orbital states arising from the $\mathrm{Ge}$ and $\mathrm{Al}$ atoms for both the $\mathrm{H}$ and $\mathrm{T}$ configurations crosses the Fermi level at the conduction band minimum. The difference between the band width of both the $\mathrm{H}$ and $\mathrm{T}$ configurations of the $\mathrm{I}_{\mathrm{Al}}$ is $0.01 \mathrm{eV}$. For the $\mathrm{Al}_{\mathrm{Ge}}$, the contribution of both $p$ - orbital states of $\mathrm{Al}$ and $\mathrm{Ge}$ atoms crosses the Fermi level at the valence band maximum (see Fig. $2 \mathrm{~g}$ ). The addition of new states by $\mathrm{Al}_{\mathrm{Ge}}$ led to a reduction of the Ge band width by $0.09 \mathrm{eV}$, suggesting a narrow band gap semiconductor material. The Al interstitial in Ge acts as $n$-type and the Al substitution in Ge acts as a $p$-type dopant. For the $\mathrm{I}_{\mathrm{Al}} \mathrm{Al}_{\mathrm{Ge}}$, in both the $\mathrm{T}$ and $\mathrm{H}$ configurations, the introduction of $\mathrm{Al}$ in a substitutional and interstitial sites, induce more states (contributed by $p$ - orbital of both $\mathrm{Al}$ and $\mathrm{Ge}$ ) in the valence band of Ge as shown in Figs $2 \mathrm{j}$ to 2l. These states are $0.02 \mathrm{eV}$ below the Fermi level. This is in contrast to the $\mathrm{I}_{\mathrm{Al}}$ where the systems tends to be semi metallic.

3.3 Formation and charge states energies of aluminium interstitials $\left(\mathrm{I}_{\mathrm{Al}}\right)$ and substitution $\left(\mathrm{Al}_{\mathrm{Ge}}\right)$ in $\mathrm{Ge}$

Table 1 lists the formation energies of the $\mathrm{I}_{\mathrm{Al}}$ (for both the $\mathrm{T}$ and $\mathrm{H}$ configurations), $\mathrm{Al}_{\mathrm{Ge}}$ and $\mathrm{I}_{\mathrm{Al}} \mathrm{Al}_{\mathrm{Ge}}$. The formation energy of the $\mathrm{I}_{\mathrm{Al}}$ in the neutral charge state, for the $\mathrm{T}$ configuration is $0.05 \mathrm{eV}$ lower than that of the $\mathrm{H}$ configuration. This implies that the $\mathrm{I}_{\mathrm{Al}}$ in the $\mathrm{T}$ configuration, under equilibrium condition is energetically more favourable than the $\mathrm{H}$ configuration. The difference between the formation energies of the $\mathrm{T}$ and $\mathrm{H}$ configurations, could be as a 
result of the amount of strain experienced by the atoms in each configuration.

The results of the neutral charge state formation energy for the $\mathrm{Al}_{\mathrm{Ge}}$ as shown in Table 1 is $-2.68 \mathrm{eV}$. As was reported by Shi et al [21], that $\mathrm{Al}$ atom in $\mathrm{Si}$ prefers energetically at a substitutional site rather than an interstitial site, for Ge the same trend is observed. The difference between the energy of formation of $\mathrm{Al}$ interstitial in $\mathrm{Ge}$ and $\mathrm{Al}$ substitution in $\mathrm{Ge}$ is at least $0.37 \mathrm{eV}$, therefore the concentration of $\mathrm{I}_{\mathrm{Al}}$ defect is much lower than that of $\mathrm{Al}_{\mathrm{Ge}}$.

Fig. 3a shows the plot of formation energies as a function of the Fermi energy for the $\mathrm{I}_{\mathrm{Al}}$ (in both the $\mathrm{T}$ and $\mathrm{H}$ configurations), the $\mathrm{Al}_{\mathrm{Ge}}$ and $\mathrm{I}_{\mathrm{Al}} \mathrm{Al}_{\mathrm{Ge}}$ (when the interstitial atom is at the $\mathrm{T}$ and $\mathrm{H}$ sites). Table 2 shows the listing of the charge state transition levels induced by $\mathrm{Al}$ defects in Ge. The $\mathrm{I}_{\mathrm{Al}}$ induced deep donor levels at $(+2 /+1)$ in both the $\mathrm{T}$ and $\mathrm{H}$ configurations. These levels are at $E_{V}+0.23$ and $E_{C}-0.35 \mathrm{eV}$ for the $\mathrm{T}$ and $\mathrm{H}$ configurations, respectively. The $\mathrm{I}_{\mathrm{Al}}$ did not induce any shallow or acceptor level for all Fermi energies within the band gap of Ge. The $\mathrm{I}_{\mathrm{Al}}$ exhibits charge state controlled metastability. The $\mathrm{Al}_{\mathrm{Ge}}$ induced only an accessible charge state transition energy level within the band gap of Ge at $(0 /-1)$, which is a shallow acceptor lying at $0.14 \mathrm{eV}$ above the valence band maximum (see Fig. 3b). For the $\mathrm{Al}_{\mathrm{Ge}}$, other charge state transition energy levels induced within the band gap of Ge, are not thermodynamically stable. The $\mathrm{Al}_{\mathrm{Ge}}$ did not induce any donor level as is observed for the $\mathrm{I}_{\mathrm{Al}}$.

3.4 Formation and charge states energies of aluminium interstitial-substitutional pair in $\mathrm{Ge}\left(\mathrm{Al}_{\mathrm{Ge}}-\mathrm{I}_{\mathrm{Al}}\right)$

According to Table 1, the neutral charge state formation energy of the $\mathrm{I}_{\mathrm{Al}} \mathrm{Al}_{\mathrm{Ge}}$ when the interstitial atom is at the $\mathrm{T}$ and $\mathrm{H}$ sites are -2.37 and $-2.32 \mathrm{eV}$, respectively. The $\mathrm{I}_{\mathrm{Al}} \mathrm{Al}_{\mathrm{Ge}}$ defect complexes have binding energies of 0.80 and 
$0.75 \mathrm{eV}$ for when the interstitial atom is at the $\mathrm{T}$ and $\mathrm{H}$ sites, respectively. The result of the binding energies according to Eq. 5, suggests that the $\mathrm{I}_{\mathrm{Al}} \mathrm{Al}_{\mathrm{Ge}}$ complex system is stable. The $\mathrm{I}_{\mathrm{Al}} \mathrm{Al}_{\mathrm{Ge}}$ defect forms with a lower formation energy when the interstitial atom is at the $\mathrm{T}$ site than when it is at the $\mathrm{H}$ site. The difference in the amount of strain experienced by the bond length of atoms in the $\mathrm{T}$ and $\mathrm{H}$ configurations, could be a key to understanding the difference in the formation energies. The lower formation energy of the neutral charge state of the $\mathrm{I}_{\mathrm{Al}} \mathrm{Al}_{\mathrm{Ge}}$ when the atom is at the $\mathrm{T}$ site shows that under equilibrium conditions, the $\mathrm{I}_{\mathrm{Al}} \mathrm{Al}_{\mathrm{Ge}}$ is energetically more favourable and its concentration is higher than that of the $\mathrm{H}$ configuration.

According to Fig. 3c, the $\mathrm{I}_{\mathrm{Al}} \mathrm{Al}_{\mathrm{Ge}}$ induced two distinct double donors at $(+2 /+1)$ and $(+1 / 0)$ charge state transition levels in the band gap of Ge for when the atom is at the $\mathrm{T}$ and $\mathrm{H}$ sites. When the interstitial atom is at the $\mathrm{T}$ site, the $(+2 /+1)$ and $(+1 / 0)$ are at energy level of $E_{V}+0.06$ and $E_{C}-0.24$ $\mathrm{eV}$, respectively. While $(+2 /+1)$ is a shallow level close to the valence band, $(+1 / 0)$ is a deep level lying almost at the middle of the band gap of Ge. When the interstitial atom is at the $\mathrm{H}$ site, the $(+2 /+1)$ and $(+1 / 0)$ are shallow levels with energies of $E_{V}+0.12$ and $E_{C}-0.10 \mathrm{eV}$, respectively. Interestingly, for the $\mathrm{I}_{\mathrm{Al}} \mathrm{Al}_{\mathrm{Ge}}$, when the interstitial atom is at the $\mathrm{T}$ site, it induced a deep level at $(+1 / 0)$, but when the interstitial atom is at the $H$ site, the $(+1 / 0)$ is a shallow level. For the $(+1 / 0)$ level, the energy difference between the $\mathrm{T}$ and $\mathrm{H}$ sites is $0.14 \mathrm{eV}$. The $\mathrm{I}_{\mathrm{Al}} \mathrm{Al}_{\mathrm{Ge}}$ induced charge state controlled metastability just as we observed for the $\mathrm{I}_{\mathrm{Al}}$.

\section{Summary}

In conclusion, we have carried out detailed calculations of $\mathrm{I}_{\mathrm{Al}}, \mathrm{Al}_{\mathrm{Ge}}$ and $\mathrm{I}_{\mathrm{Al}} \mathrm{Al}_{\mathrm{Ge}}$ complexes in Ge using a hybrid functional (HSE06) in the framework of density 
functional theory (DFT). We calculated the formation energies and charge state transition energies of the $\mathrm{I}_{\mathrm{Al}}$ (for the tetrahedral $(\mathrm{T})$ and hexagonal $(\mathrm{H})$ configurations), $\mathrm{Al}_{\mathrm{Ge}}$ and $\mathrm{I}_{\mathrm{Al}} \mathrm{Al}_{\mathrm{Ge}}$ (for two configurations: when the interstitial atom is at the tetrahedral $(\mathrm{T})$ site or the hexagonal $(\mathrm{H})$ site). The results of the formation energy of the $\mathrm{I}_{\mathrm{Al}}$ reveals that the $\mathrm{T}$ configuration is more stable in the neutral charge state than the $\mathrm{H}$ configuration. Under equilibrium condition, the $\mathrm{I}_{\mathrm{Al}} \mathrm{Al}_{\mathrm{Ge}}$ is energetically more stable with binding energy of $0.80 \mathrm{eV}$, when the interstitial atom is at the $\mathrm{T}$ site. While the $\mathrm{Al}_{\mathrm{Ge}}$ induced a shallow acceptor level, at $E_{V}+0.14 \mathrm{eV}$, the $\mathrm{I}_{\mathrm{Al}}$ induced a deep donor level at $E_{V}+0.23$ and $E_{C}-0.35 \mathrm{eV}$ for both the $\mathrm{T}$ and $\mathrm{H}$ configurations, respectively. The $\mathrm{I}_{\mathrm{Al}} \mathrm{Al}_{\mathrm{Ge}}$ induced a shallow double donor level in the band gap of Ge at $E_{V}+0.06$ and $E_{V}+0.12$ for when the interstitial atom is at the $\mathrm{T}$ and $\mathrm{H}$ sites, respectively. The $\mathrm{I}_{\mathrm{Al}}$ and $\mathrm{I}_{\mathrm{Al}} \mathrm{Al}_{\mathrm{Ge}}$ display properties of charge state controlled metastability. We expect the result provided in this report to provide a frontier insight for experimental investigation of $\mathrm{Al}$ related defect complexes in Ge.

\section{Acknowledgement}

This work is based on the research supported partly by National Research foundation (NRF) of South Africa (Grant specific unique reference number (UID) 98961). The opinions, findings and conclusion expressed are those of the authors and the NRF accepts no liability whatsoever in this regard.

\section{References}

1. C. Claeys, E. Simoen, 2nd edn. (Elsevier, 2011)

2. F.J. Morin, J.P. Maita, Phys. Rev. 94, 1525 (1954)

3. F.D. Auret, S.M.M. Coelho, M. Hayes, W.E. Meyer, J.M. Nel, physica status solidi (a) 205(1), 159 (2008)

4. E. Simoen, J. Vanhellemont, Journal of Applied Physics 106(10), (2009) 
5. F. Auret, P.J. van Rensburg, M. Hayes, J. Nel, S. Coelho, W. Meyer, S. Decoster, V. Matias, A. Vantomme, D. Smeets, Nuclear Instruments and Methods in Physics Research Section B: Beam Interactions with Materials and Atoms 257(1), 169 (2007)

6. F. Auret, S. Coelho, G. Myburg, P.J. van Rensburg, W. Meyer, Physica B: Condensed Matter 404(22), 4376 (2009)

7. J. Vanhellemont, P. Śpiewak, K. Sueoka, Journal of Applied Physics 101(3), (2007)

8. P. Deák, B. Aradi, T. Frauenheim, E. Janzén, A. Gali, Phys. Rev. B 81, 153203 (2010)

9. M. Kuisma, J. Ojanen, J. Enkovaara, T. Rantala, Physical Review B 82(11), 115106 (2010)

10. P. Hohenberg, W. Kohn, Phys. Rev. 136, B864 (1964)

11. W. Kohn, Journal of computational chemistry 20(1), 1 (1999)

12. A. Carvalho, R. Jones, C. Janke, J.P. Goss, P.R. Briddon, J. Coutinho, S. Öberg, Phys. Rev. Lett. 99, 175502 (2007)

13. C. Janke, R. Jones, S. Öberg, P.R. Briddon, Phys. Rev. B 75, 195 (2007)

14. E. Igumbor, C. Ouma, G. Webb, W. Meyer, Physica B: Condensed Matter 480, 191 (2016)

15. J. Coutinho, S. Öberg, V.J.B. Torres, M. Barroso, R. Jones, P.R. Briddon, Phys. Rev. B 73, $235213(2006)$

16. E. Igumbor, W. Meyer, Materials Science in Semiconductor Processing 43, 129 (2016)

17. E. Igumbor, R.E. Mapasha, R. Andrew, W.E. Meyer, Computational Condensed Matter $\mathbf{8}, 31(2016)$

18. A. Chroneos, R. Grimes, C. Tsamis, Materials science in semiconductor processing $\mathbf{9}(4)$, $536(2006)$

19. A. Chantre, D. Bois, Physical Review B 31(12), 7979 (1985)

20. L. Song, B. Benson, G. Watkins, Applied physics letters 51(15), 1155 (1987)

21. T. Shi, W.J. Yin, Y. Wu, M. Al-Jassim, Y. Yan, Journal of Applied Physics 114(6), $063520(2013)$

22. J. Heyd, G.E. Scuseria, M. Ernzerhof, The Journal of Chemical Physics 118(18), 8207 (2003)

23. G. Kresse, J. Furthmüller, Phys. Rev. B 54, 11169 (1996)

24. G. Kresse, D. Joubert, Physical Review B 59(3), 1758 (1999)

25. G. Kresse, J. Furthmüller, Computational Materials Science 6(1), 15 (1996)

26. P.E. Blöchl, Physical Review B 50(24), 17953 (1994)

27. J.P. Perdew, K. Burke, M. Ernzerhof, Phys. Rev. Lett. 77, 3865 (1996)

28. H. Tahini, A. Chroneos, R. Grimes, U. Schwingenschlögl, H. Bracht, Applied Physics Letters 99(7), 072112 (2011) 
29. E. Igumbor, K. Obodo, W.E. Meyer, Solid State Phenomena 242, 440 (2015)

30. P. Śpiewak, J. Vanhellemont, K. Sueoka, K. Kurzydłowski, I. Romandic, Materials Science in Semiconductor Processing 11(5), 328 (2008)

31. S.B. Zhang, J.E. Northrup, Phys. Rev. Lett. 67, 2339 (1991)

32. Freysoldt, Christoph, Grabowski, Blazej, Hickel, Tilmann, J. Neugebauer, Kresse, Georg, Janotti, Anderson, V. de Walle, C. G., Rev. Mod. Phys. 86, 253 (2014)

33. C. Freysoldt, J. Neugebauer, C.G. Van de Walle, Physical review letters 102(1), 016402 (2009)

34. C. Freysoldt, J. Neugebauer, C.G. Van de Walle, physica status solidi (b) 248(5), 1067 (2011)

35. G. Zollo, Y.J. Lee, R.M. Nieminen, Journal of Physics: Condensed Matter 16(49), 8991 (2004)

36. A. Chroneos, B. Uberuaga, R. Grimes, Journal of Applied Physics 102(8), 083707 (2007) 


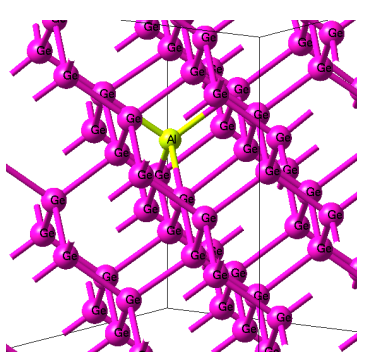

(a)

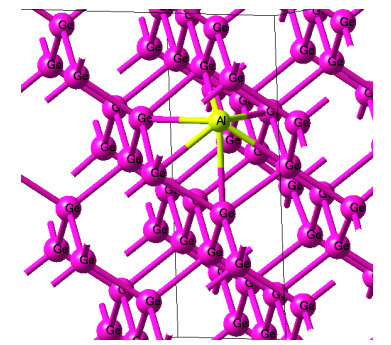

(b)

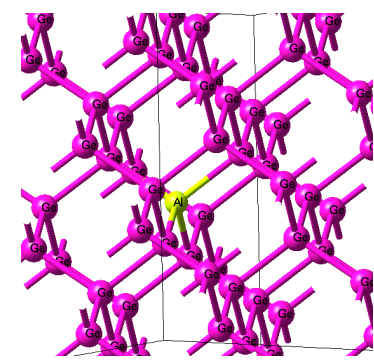

(c)

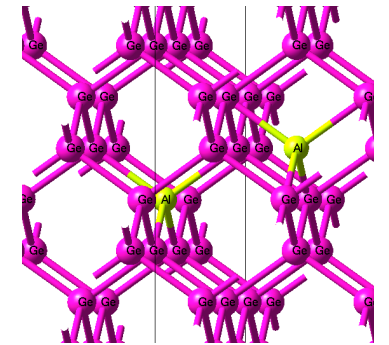

(d)

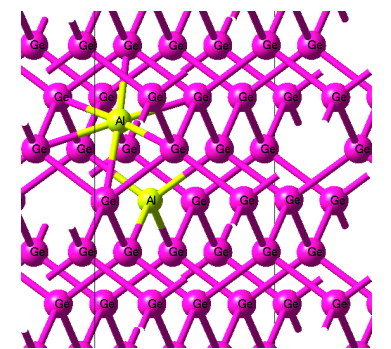

(e)

Fig. 1 The fully relaxed geometric structures of the (a) $I_{A l}$ for the $T$ configuration; (b) $I_{A l}$ for the $\mathrm{H}$ configuration; (c) $\mathrm{Al}_{\mathrm{Ge}}$; (d) $\mathrm{I}_{\mathrm{Al}} \mathrm{Al}_{\mathrm{Ge}}$ interstitial-substitutional pairs (interstitial atom at the $\mathrm{T}$ site); and (e) $\mathrm{I}_{\mathrm{Al}} \mathrm{Al}_{\mathrm{Ge}}$ interstitial-substitutional pairs (interstitial atom at the $\mathrm{H}$ site).

Table 1 The calculated formation energies $\left(E^{f}\right)$ in $\mathrm{eV}$ at $\epsilon_{f}=0$. For the $\mathrm{Al}_{\mathrm{Ge}}, \mathrm{I}_{\mathrm{Al}}$ and $\mathrm{I}_{\mathrm{Al}} \mathrm{Al}_{\mathrm{Ge}}$. The configuration with the lowest formation energy is written in bold. The last column lists the binding energies $(\mathrm{eV})$ for the defect-complex systems.

\begin{tabular}{cccc}
\hline \hline Defect & Configuration & Neutral charge state & Binding energy \\
\hline $\mathrm{Al}_{\mathrm{Ge}}$ & & -2.68 & - \\
\hline $\mathrm{I}_{\mathrm{Al}}$ & $\mathrm{T}$ & $\mathbf{0 . 1 8}$ & - \\
& $\mathrm{H}$ & 0.19 & 0.80 \\
& $\mathrm{~T}$ & $\mathbf{- 2 . 3 7}$ & 0.75 \\
\hline $\mathrm{I}_{\mathrm{Al}} \mathrm{Al}_{\mathrm{Ge}}$ & $\mathrm{T}$ & -2.32 & \\
& $\mathrm{H}$ & &
\end{tabular}

Table 2 The energy (eV) of the charge state transition levels $\epsilon\left(q / q^{\prime}\right)$ with reference to the valence band maximum $\left(\mathrm{E}_{\mathrm{V}}\right)$ and the conduction band minimum $\left(\mathrm{E}_{\mathrm{C}}\right)$, for the $\mathrm{I}_{\mathrm{Al}}, \mathrm{Al}_{\mathrm{Ge}}$ and $\mathrm{I}_{\mathrm{Al}} \mathrm{Al}_{\mathrm{Ge}}$.

\begin{tabular}{cccc}
\hline \hline Defect & Configuration & Charge state transition level & Energy level \\
\hline $\mathrm{I}_{\mathrm{Al}}$ & $\mathrm{T}$ & $(+2 /+1)$ & $\mathrm{E}_{\mathrm{V}}+0.23$ \\
& $\mathrm{H}$ & $(+2 /+1)$ & $\mathrm{E}_{\mathrm{C}}-0.35$ \\
\hline $\mathrm{Al}_{\mathrm{Ge}}$ & - & $(0 /-1)$ & $\mathrm{E}_{\mathrm{V}}+0.14$ \\
\hline $\mathrm{I}_{\mathrm{Al}} \mathrm{Al}_{\mathrm{Ge}}$ & $\mathrm{T}$ & $(+2 /+1)$ & $\mathrm{E}_{\mathrm{V}}+0.06$ \\
& & $(+1 / 0)$ & $\mathrm{E}_{\mathrm{C}}-0.24$ \\
\hline $\mathrm{I}_{\mathrm{Al}} \mathrm{Al}_{\mathrm{Ge}}$ & $\mathrm{H}$ & $(+2 /+1)$ & $\mathrm{E}_{\mathrm{V}}+0.12$ \\
& & $(+1 / 0)$ & $\mathrm{E}_{\mathrm{C}}-0.10$ \\
\hline \hline
\end{tabular}




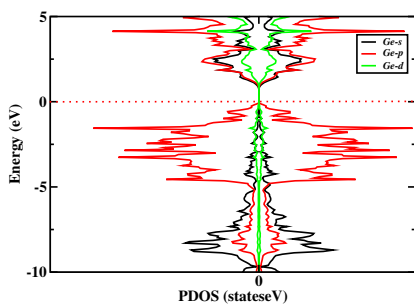

(a)

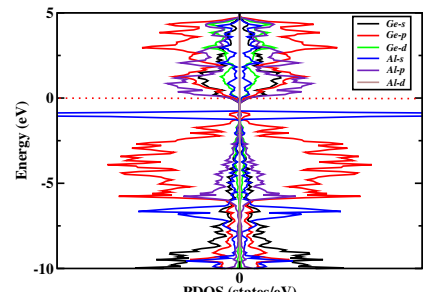

(c)

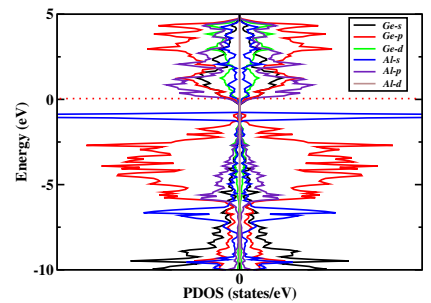

(e)

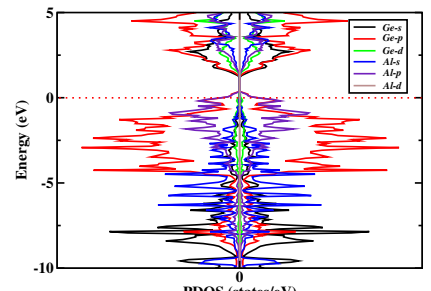

(g)

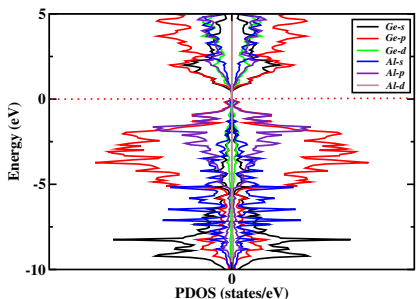

(i)

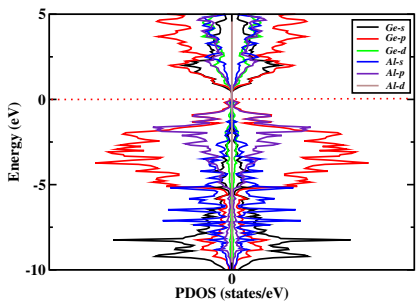

(k)

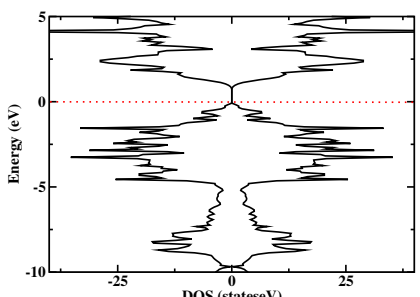

(b)

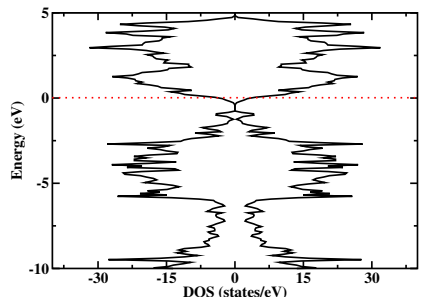

(d)

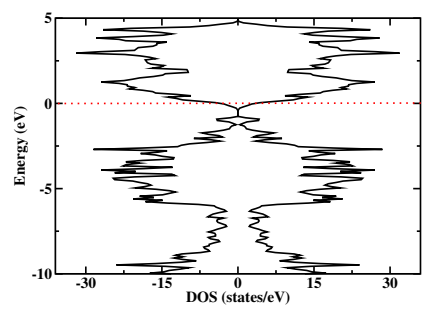

(f)

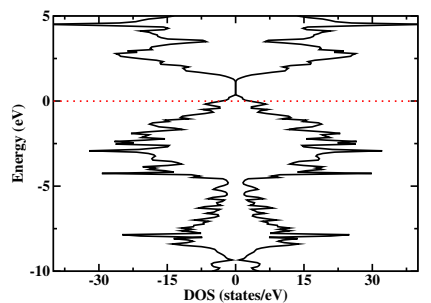

(h)

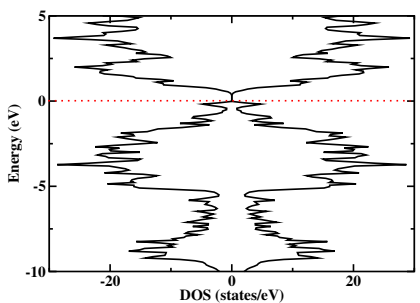

(j)

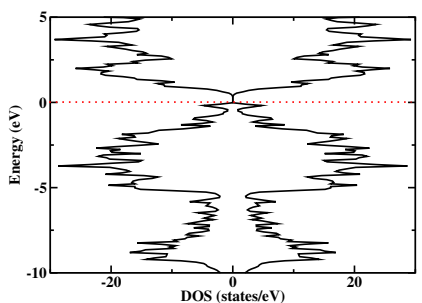

(1)

Fig. 2 Plot showing the spin polarised partial (PDOS) and total density of states (DOS) of the Al impurities and interstitial-substitutional complexes in Ge. The Fermi level (at $\epsilon_{f}=0$ $\mathrm{eV}$ ) is shown by the dashed horizontal red line. (a) PDOS of pristine Ge, (b) Total DOS of pristine Ge, (c) PDOS of $\mathrm{I}_{\mathrm{Al}}$, for T configuration, (d) Total DOS of $\mathrm{I}_{\mathrm{Al}}$, for $\mathrm{T}$ configuration, (e) PDOS of $\mathrm{I}_{\mathrm{Al}}$, for $\mathrm{H}$ configuration, (f) Total DOS of $\mathrm{I}_{\mathrm{Al}}$, for $\mathrm{H}$ configuration, (g) PDOS of $\mathrm{Al}_{\mathrm{Ge}}$, (h) Total DOS of $\mathrm{Al}_{\mathrm{Ge}}$, (i) PDOS of $\mathrm{I}_{\mathrm{Al}} \mathrm{Al}_{\mathrm{Ge}}$, for interstitial atom at $\mathrm{T}$ site, $(\mathrm{j})$ Total DOS of $\mathrm{I}_{\mathrm{Al}} \mathrm{Al}_{\mathrm{Ge}}$, for interstitial atom at $\mathrm{T}$ site, $(\mathrm{k})$ PDOS of $\mathrm{I}_{\mathrm{Al}} \mathrm{Al}_{\mathrm{Ge}}$, for interstitial atom at $\mathrm{H}$ site and (l) Total DOS of $\mathrm{I}_{\mathrm{Al}} \mathrm{Al}_{\mathrm{Ge}}$, for interstitial atom at $\mathrm{H}$ site. 


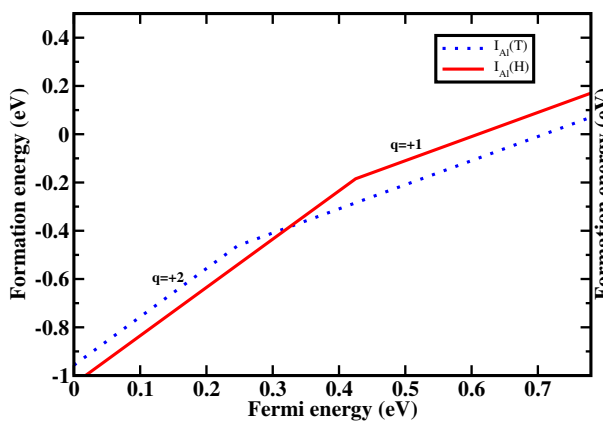

(a)

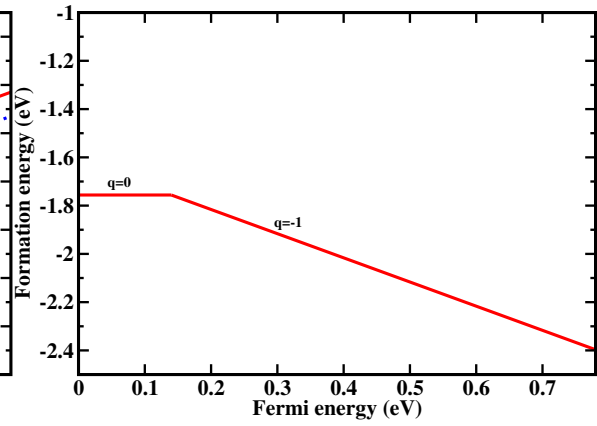

(b)

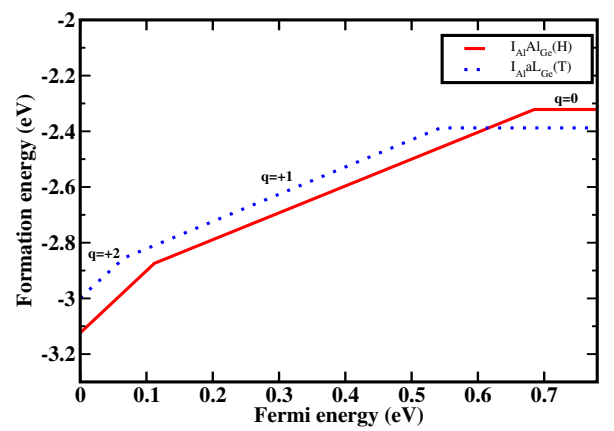

(c)

Fig. 3 Plot of formation energies as a function of the Fermi energy $\left(\varepsilon_{F}\right)$ for (a) $\mathrm{I}_{\mathrm{Al}}$, (b) $\mathrm{Al}_{\mathrm{Ge}}$ and (c) $\mathrm{I}_{\mathrm{Al}} \mathrm{Al}_{\mathrm{Ge}}$ (when the interstitial atom is at the $\mathrm{T}$ and $\mathrm{H}$ sites) defect. The plot indicates different charge state transition levels observed in the band gap. 